\title{
Effectiveness of a diode laser in addition to non-surgical periodontal therapy: study of intervention
}

\author{
Antonio Crispino, DDS, PhD \\ Michele Mario Figliuzzi, DDS, PhD \\ Claudio lovane, DDS \\ Teresa Del Giudice, MD \\ Simona Lomanno \\ Delfina Pacifico, DDS \\ Leonzio Fortunato, MD \\ Roberto Del Giudice, DDS
}

Department of Periodontics and Oral Sciences, "Magna Graecia" University, Catanzaro, Italy

Corresponding author:

Antonio Crispino

Department of Periodontics and Oral Sciences, "Magna Graecia" University

Via Tommaso Campanella, 115

88100 Catanzaro, Italy

E-mail: crispino@unicz.it

\section{Summary}

Background. Chronic periodontitis affects $47 \%$ of adult population over the age of 30 . The first phase of periodontal treatment is always represented by scaling and root planning (SRP), that is a causal, non-surgical therapy that recognizes as primary aims the control of bacterial infection and the reduction of periodontal plaque-associated inflammation. Yet, another innovative causal therapy is represented by the irradiation of periodontal pockets with laser.

Aim. To evaluate the effect of a $940-\mathrm{nm}$ diode laser as an adjunct to SRP in patients affected by periodontitis.

Materials and methods. Sixty-eight adult patients with moderate-to-severe periodontitis were sequentially enrolled and undergone to periodontal examination (V1) in order to detect gingival index (GI), plaque index (PI) and probing depth (PD). The patients were randomly divided into two groups: the first $(n=34)$ received SRP treatment alone, the control group $(n=34)$ received SRP and 940-nm diode laser therapy.

Results. Data were analyzed by Student's t-test, with two tails; for all clinical parameters, both groups reported statistically significant differences compared to basal values $(p<0.0001)$. Both procedures were effective in improving GI, PI and PD, but the use of diode laser was associated with more evident results.
Conclusions. Considered the better clinical outcomes, diode laser can be routinely associated with SRP in the treatment of periodontal pockets of patients with moderate-to-severe periodontitis.

Key words: periodontal diseases, diode laser, scaling, root planning.

\section{Introduction}

The periodontal disease is a chronic inflammatory process, characterized by bacterial etiology and cyclic evolution, which determines a progressive, site-specific destruction of the supporting tissues of the tooth, and proceeds from the superficial periodontium (gum) to the deep periodontium (alveolar bone, periodontal ligament, cementum), resulting in typical pathological lesions (periodontal pockets, gingival recessions, vertical and/or horizontal bone resorption, bifurcation lesions) to the loss of the dental element (1).

From the epidemiological point of view, in the United States of America chronic periodontitis affects $47 \%$ of the adult population over the age of 30 , distributed in mild $(9 \%)$, moderate $(30 \%)$ and severe $(8 \%)(2)$.

Although a number of risk factors can influence the start, progression and prognosis of periodontitis (age, sex, cigarette smoking, hormonal changes, immune system disorders, systemic diseases, diabetes, stress) (3-5), the main etiological factor is represented by dental plaque and in particular by anaerobic gram-negative bacilli (6). For that reason, the first phase of periodontal treatment is always represented by the initial preparation, which is a type of etiological, non-surgical therapy, which recognizes as primary aims the elimination or reduction of bacterial infection and the control of periodontal plaque-associated inflammation (7). We choosed to use laser therapy to personally verify the actual efficiency, where the literature talks to us for a long time, of this treatment option in the treatment of periodontally compromised patients and to evaluate their satisfaction. In addition to SRP the use of laser therapy, as shown by several studies, appears to improve and facilitate the healing of treated sites. Recently, Yilmaz et al. (2013) have shown that in the sites treated with the use of laser Er:YAG in addition to $\mathrm{SRP}$, reached statistically significant improvements in terms of attachment gain and reduction in PD compared to sites treated with only srp or only topical gaseous ozone (8). Other study that compares, like treatment options, Nd:YAG laser alone, SRP alone, and $\mathrm{Nd}$ :Yag plus SRP has demonstrated that the last option of treatment is the best in term of reduction of 
PI, GI, PPD and GCF volume values (9). Another type of laser (KTP: potassium-titanyl-phosphate) has shown to be a significant help in SRP, like demonstrated in a study of Romeo et al. (2010). In this study, treated sites are divided into four groups and the best results were obtained in the groups in which the laser has been used (10). A diode laser has a wavelength of 810-980 Nm, and there are many different laser used in periodontology with a different wavelength; Ktp laser has a wavelength of $532 \mathrm{Nm}$, Nd:YAG laser of 1064 $\mathrm{Nm}$, Er:Yag of $2940 \mathrm{Nm}$ and CO2 laser of 9600-10600 $\mathrm{Nm}$ (11). We used diode laser cause has an easier learning curve and a more affordable price than others.

\section{Aim of the study}

To check and compare the possible improvement of the periodontal indices in two groups of patients with periodontal disease: the first group undergone to SRP, the second one to SRP with the addition of laser therapy.

\section{Materials and methods}

At the Department of Dentistry of the University Hospital "Mater Domini" of Catanzaro, sixty-eight adult patients (mean age of 56,3 years) with moderate-tosevere periodontal disease were sequentially enrolled on a voluntary basis. Totally 1224 sites with periodontal disease are treated.

The selected cases were based on the following inclusion criteria: 1) patients 18 or older; 2) single or multirooted teeth; 3 ) patients that received the same laser treatment including: laser settings, procedural steps and technique; 4) patients who undergone, after 4 months, to follow-up and 5) patients that had no surgery for 12 months prior to treatment. There was no exclusion of smokers or patients with medical conditions.

After having obtained a thorough medical and dentistry anamnesis and the underwriting of a specific informed consent, all the patients underwent a periodontal examination (V1), in order to detect the most common indices of periodontal health. The experimentation has followed the principles of Declaration of Helsinki.

The degree of gingival inflammation was assessed by gingival index (GI) of Löe and Silness (1967) (12), measured from 0 to 3 on each tooth:

- $0=$ healthy gingiva

- 1 = mild inflammation, absence of bleeding on probing

- 2 = moderate inflammation, bleeding on probing

- 3 = severe inflammation, spontaneous bleeding.

The level of hygiene was assessed by plaque index

(PI) of Silness and Löe (1964) (13):

- 0 = absence of plaque

- 1 = presence of plaque detectable with probe

- 2 = moderate accumulation of plaque, which is visible to the naked eye

- 3 = abundant accumulation of plaque.
GI and PI were detected on 6 index teeth: 12, 16, 24, 32, 36, 44.

It was then measured the pocket depth (PD), which consists in measuring the distance in $\mathrm{mm}$ between the free gingival margin and the base of the pocket, making six records for each dental element: mesial, central and distal probing of the buccal and lingualpalatal sides of all teeth (14). The values in $\mathrm{mm}$ of the survey were then converted into a score called T-score:

- 0 = PD between 0 and $2 \mathrm{~mm}$

- 1 = PD between 2 and $4 \mathrm{~mm}$

- 2 = PD between 4 and $6 \mathrm{~mm}$

- 3 = PD over $6 \mathrm{~mm}$.

After having filled a complete medical records, patients were randomly divided into two treatment groups.

The patients of the first group $(n=34)$ received initial preparation. It consists in the mechanical instrumentation of the root surface, in order to make it biologically compatible with the healing of periodontal tissues; that is made possible by two fundamental procedures:

- scaling, which consists in removing mucobacterial plaque and tartar from supragingival and subgingival tooth surfaces, generally through the use of inserts fixed on an ultrasonic scaler;

- root planning, which consists in the removal of deposits of subgingival calculus, granulation tissue and softened, infected or necrotic cementum, eliminating the irregularities of the root surface to make it smooth and hard, typically through the use of manual tools such as the curettes.

The second group of patients $(n=34)$ received the same therapy did in the first group, but with the addition of laser therapy through a $940 \mathrm{~nm}$ diode laser (ezlase ${ }^{\mathrm{TM}}$ soft tissue diode laser - Biolase Technology Inc.). This laser is extremely compact and easy to handle; the active medium is a semiconductor and the pumping system is an electric current (15); the wavelength's laser of $940 \mathrm{~nm}$ makes it considerably affine to molecules of hemoglobin and melanin (16).

The operating protocol of the treatment of periodontal pockets in by $940 \mathrm{~nm}$ diode laser provides for the application of the following dosimetric values:

- power: $3 \mathrm{~W}$

- pulse frequency: $15 \mathrm{~Hz}$

- fluence: $1,2 \mathrm{~J} / \mathrm{mm}^{2}$

- emission mode of laser light: pulsed

- $\quad$ on time (pulse duration): $10 \mathrm{~ms}$

- time-off (relaxation time): $20 \mathrm{~ms}$

- average power: $1 \mathrm{~W}$

- optical diameter fiber and tips: 300-400 $\mu$.

The pulsed emission has two important clinical advantages:

- enables the thermal relaxation during the time-off, avoiding the overheating and charring of radiated tissues;

- allows to operate without the use of anesthesia. Treatment should not begin before all the people in the room have not been wearing protective glasses. 
After connecting all the components (pedal and optical fiber), it is essential to activate the tip on a dark cardboard (e.g., blue articulation paper) and check that the spot of the light guide designs a perfect circle, making sure that it has not a star-shaped appearance; the activated tip presents a blackened and, at this point, the laser is ready for use. Given the high affinity of the $940 \mathrm{~nm}$ diode laser for dark colors, we were able to increase the bactericidal effect just irrigating the site to be treated with an exogenous chromophore, that is a pigmented substance that makes the tissues more suscettible to the light of the diode laser. Substances such as povidone-iodine (Betadine ${ }^{\circledR}$ ) and methylene blue contribute to reduce the bacterial load due to their disinfectant power; moreover these pigments bind to the cytoplasmic membrane of bacteria, making them darker $(17,18)$. So you have just to irrigate the quadrant to be treated with such substances and wait 30 seconds, without rinsing. Therefore fit the tip within the periodontal pocket, keeping at about $1 \mathrm{~mm}$ from the bottom of the same and in the parallel direction to the long axis of the tooth to be treated. The tips have a metal core which allows their inclination according to the needs of the operator and to the spatial arrangement of the pocket. Once the light beam is activated, the tip must be moved within the pocket in both horizontal and vertical directions, as to draw a pattern, with rapid movements, leading the tip toward the inner wall of the pocket, in order to remove junctional epithelium migrated and induce bleeding necessary for the formation of a clot. It is recommended to make for each pocket 3 cycles of irradiation, each lasting $30 \mathrm{sec}-$ onds. It is important during the treatment to maintain the aspirator near the site, to avoid overheating. When you remove the tip from the pocket, it might have residues of sulcular epithelium and infected granulation tissue, in which case you need to clean it up with a gauze soaked in disinfectant before proceeding to the next pocket.

The clinical follow-up has been executed, in both groups, after 4 months of treatment (V4). After an appropriate causal non-surgical therapy and an adequate oral hygiene at home by the patient, periodontal tissues undergo a healing process that is completed after an average of 3 months. In particular, it assists to:

- reduction in probing depth (PD), due to recollagenation of the supracrestal fibers, obviously in function variable depending on the depth of initial probing $(19,20)$;

- reduction in gingival index (GI) and bleeding on probing, due to the reduction of the inflammatory infiltrate;

- reduction in the plaque index $(\mathrm{PI})$ and change of supra- and subgingival bacterial flora, with a decrease of Gram-negative and an increase Grampositive $(21,22)$.

Data were analyzed by Student's T test with two tails. For all clinical parameters considered, both treatment groups reported statistically significant differences compared to baseline $(p<0.0001)$.

\section{Results}

The biggest difference was found relatively to the average gingival index (GI). In the group of patients undergoing initial preparation alone, such clinical parameter decreased from the value of 1.6 to the value of 0.9 , with a reduction of $44 \%$ as average, while in the group of subjects treated with diode laser, the average gingival index was turned from the value of 1.5 to 0.3 , demonstrating a decrease of $80 \%$; therefore the addition of the laser-therapy allows to reduce the average gingival index than double the SRP alone (80 vs $44 \%$ ).

Plaque index and probing depths were reduced by a mean of 57 and $58 \%$ in the group of patients receiving SRP alone, while in the group of patients undergoing SRP + laser therapy, PI and PD underwent a mean percentage decrease of 67 and $76 \%$.

Ultimately, the results of this study clearly shows that both procedures are effective in improving periodontal indices (GI, PI, PD) compared to basal values, but the association of the diode laser to the initial preparation allows to obtain clinical results more evident than the single procedure of SRP (Tabs. 1, 2).

Table 1. Results of Group I (SRP therapy).

\begin{tabular}{lll}
\hline Parameter & Middle Value & P \\
\hline Average PI $\left(\mathrm{V}_{1}\right)$ & 2,1 & $<0.0001$ \\
Average PI $\left(\mathrm{V}_{4}\right)$ & 0,9 & $<0.0001$ \\
\hline Average GI $\left(\mathrm{V}_{1}\right)$ & 1,6 & \\
Average GI $\left(\mathrm{V}_{4}\right)$ & 0,9 & $<0.0001$ \\
\hline Average PD $\left(\mathrm{V}_{1}\right)$ & 2,6 & \\
Average PD $\left(\mathrm{V}_{4}\right)$ & 1,1 & \\
\hline
\end{tabular}

Table 2. Results of Group II (SRP and laser therapy).

\begin{tabular}{lll}
\hline Parameter & Middle Value & P \\
\hline Average PI $\left(\mathrm{V}_{1}\right)$ & 1,5 & $<0.0001$ \\
Average PI $\left(\mathrm{V}_{4}\right)$ & 0,5 & $<0.0001$ \\
\hline Average GI $\left(\mathrm{V}_{1}\right)$ & 1,5 & $<0.0001$ \\
Average GI $\left(\mathrm{V}_{4}\right)$ & 0,3 & \\
\hline Average PD $\left(\mathrm{V}_{1}\right)$ & 1,7 & \\
Average PD $\left(\mathrm{V}_{4}\right)$ & 0,4 & \\
\hline
\end{tabular}

\section{Discussion}

The remarkable difference between the two procedures in improving periodontal variables is attributable to the benefits from the use of diode laser in addition to the traditional procedures of SRP in the treatment of periodontal pockets $(23,24)$. They are:

- bactericidal effect;

- curettage effect;

- bio-stimulating effect.

Combining laser therapy with conventional procedures is in fact achieved a more effective decontamination of the pocket, with also a recolonization slower than sites treated only mechanically (25-29); some 
Authors attribute this phenomenon to clot formation in the pocket, that would act as a seal to it.

Thanks to curettage effect, the laser eliminates the sulcular epithelium infected in a total and complete way than conventional methods of treatment with manual tools (30), without any kind of damage to the underlying connective tissue and reducing the bacterial load of Actinobacillus actinomycetemcomitans and Porphyromonas gingivalis (31), which easily penetrate within the sulcular epithelium. Furthermore there is a scientific evidence on the direct antimicrobial effect of diode laser against levels of Targeted Periodontal Pathogens (32). According to Kreisler (2005) the greatest reduction in the degree of tooth mobility and probing depth in the group of patients who underwent SRP + laser therapy can be mainly attributed not to the killing of bacteria in periodontal pockets, but rather to the complete removal of infected sulcular epithelium, which leads to greater attack of the connective tissue (33). Furthermore, the removal of granulation tissue infected promotes the healing of connective tissue with a decrease in probing depth, gingival index and tooth mobility and a recovery of clinical attacks significantly higher compared to the initial preparation only (33-36); these results, in addition to being the best, are longer lasting and more stable over time (37). However, according to De Micheli (2011) the results of the two therapeutic procedures are similar with regard to plaque index and bleeding on probing, for which laser therapy does not lead to additional benefits (38). Also according to Dukic (2012) the results of the two treatments are similar in terms of plaque index, bleeding on probing and clinical attachment level: the addition of laser therapy showed a marked improvement in PD, but only in periodontal pockets of moderate depth (from 4 to $6 \mathrm{~mm}$ ) (39).

Finally, because of the biostimulant effect (29,40-42), laser therapy induces the acceleration of mitotic processes within the irradiated tissues, without causing structural and/or functional alterations. According to the studies of Benedicenti (2008), the laser would stimulate mitochondrial activity, with a production of intracellular ATP $>22 \%$ in irradiated cells compared to those not exposed to radiant energy, resulting in a halving of the times of cell duplication (43). In an in vitro study of Soares et al. (2013) has been demonstrated as low-level laser irradiation (LLLI) has a positive stimulatory effect on the proliferation of human periodontal ligament stem cells. This study was carried out on two healthy permanent third molars extracted due to surgical indication (44). Conlan (1996) found an increase of about $50 \%$ of the proliferation and differentiation of fibroblasts and collagen synthesis within the periodontal ligament (45), which process, according to Choi (2010) begins to manifest between the next 24-48 hours to laser treatment, and intensifies especially after the 72 hours (46); all these reactions accelerate the healing process and encourages a speedy recovery in clinical attachment.

In addition, Castro (2006) conducted a study on the histological evaluation of the use of the diode laser in vivo in addition to SRP procedures, analyzing the following parameters: residual debris, root surface morphology, thermal side effects; he concluded that the laser therapy does not cause any mechanical alteration or thermal damage to the cementum (47).

Regarding the tolerance and compliance of the patient, the laser therapy of periodontal pockets does not involve discomfort or intraoperative pain, nor requires, as a rule, the execution of loco-regional anesthesia, since the power values provided are relatively low (3 W) and the energy is supplied in pulsed mode (41).

While recognizing these indisputable results, it should be stressed, however, that the laser acts only as an adjunct to etiological non-surgical periodontal therapy, not being able to replace traditional mechanical procedures of SRP; in this regard, the study of Kamma et al. (2009) showed that combining mechanical treatment (SRP) with diode laser therapy produces better results than the laser therapy alone, both in clinical (probing depth and clinical attachment level) and bacteriological terms (total bacterial count of periodontal pathogens) (20).

\section{Conclusions}

The results show the adjunctive benefits that diode laser treatment can provide when it is used as an adjunct to non surgical periodontal treatment.

Considered the better clinical results, the laser diode can be routinely associated with the traditional mechanical non-surgical therapy (SRP) in the treatment of periodontal pockets of patients with moderate-tosevere chronic periodontitis.

The results of such studies encourage us in hoping that the use of complementary low power laser in the future will become a part of the standard protocol of non-surgical periodontal therapy.

\section{References}

1. Mitchell DA, Mitchell L. Oxford handbook of clinical dentistry. Oxford University Press, 4th ed; Oxford 2003.

2. Eke PI, Dye BA, Wei L, Thornton-Evans GO, Genco RJ. On behalf of the participating members of the CDC Periodontal Disease Surveillance workgroup: James Beck, Gordon Douglass, Roy Page. Prevalence of Periodontitis in Adults in the United States: 2009 and 2010. J Dent Res. 2012 Oct; 91(10):914-920.

3. Heitz-Mayfield LJ. Disease progression: identification of highrisk groups and individuals for periodontitis. J Clin Periodontol. 2005;32Suppl 6:196-209.

4. Krejci CB, Bissada NF. Periodontitis- the risks for its development. Gen Dent. 2000 Jul-Aug;48(4):430-6; quiz 437-8.

5. Timmerman MF, van der Weijden GA. Risk factors for periodontitis. Int J Dent Hyg. 2006 Feb;4(1):27.

6. Haffajee AD, Socransky SS. Microbial etiological agents of destructive periodontal diseases. Periodontol. 2000. 1994 Jun;5:78-111.

7. Drisko $\mathrm{CH}$. Nonsurgical periodontal therapy. Periodontol. 2000. 2001;25:77-88

8. Yilmaz S, Algan S, Gursoy H, Noyan U, Kuru BE, Kadir T. Evaluation of the clinical and antimicrobial effects of the 
Er:YAG laser or topical gaseous ozone as adjuncts to initial periodontal therapy. Photomed Laser Surg. 2013 Jun;31(6):293-298.

9. Qadri T, Tunér J, Gustafsson A. Significance of scaling and root planning with and without adjunctive use of a watercooled pulsed Nd:YAG laser for the treatment of periodontal inflammation. Lasers Med Sci. 2013 Sep 14.

10. Romeo U, Palaia G, Botti R, Leone V, Rocca JP, Polimeni A. Non surgical periodontal therapy assisted by potassiumtitanyl-phosphate laser: a pilot study. Laseres Med Sci. 2010 Nov;25(6)891-9.

11. Iaria G, Frati A. Il laser in odontoiatria e in chirurgia orale. Ed UTET, Milano. 2001.

12. Löe H. The Gingival Index, the Plaque Index and the Retention Index Systems. J Periodontol. 1967 Nov-Dec; 38(6):Suppl:610-6.

13. Silness J, Löe H. Periodontal disease in pregnancy. II. Correlation between oral hygiene and periodontal condition. Acta Odontol Scand. 1964;22:112-35.

14. Ramfjord SP. Indices for prevalence of periodontal disease. J Periodontol. 1959;30:51-9.

15. Guida L, Gaeta GM, luorio G, Boccalatte A. Laser in periodontology: theoretical-experimental approach. 1. The laser system: definition, function, classification. Arch Stomatol (Napoli). 1990 Apr-Jun;31(2):169-78.

16. lyer VH, Farista S. Management of Hyperpigmentation of lips with 940 nm Diode Laser: Two Case Report. Int J Laser Dent. 2014;4(1):31-38.

17. Hoang $T$, Jorgensen MG, Keim RG, Pattison AM, Slots J. Povidone-iodine as a periodontal pocket disinfectant. J Periodontal Res. 2003 Jun;38(3):311-7.

18. Rosling B, Hellström MK, Ramberg P, Socransky SS, Lindhe $\mathrm{J}$. The use of PVP-iodine as an adjunct to non-surgical treatment of chronic periodontitis. J Clin Periodontol. 2001 Nov;28(11):1023-31.

19. Hämmerle $\mathrm{CH}$, Joss $\mathrm{A}$, Lang NP. Short-term effects of initial periodontal therapy (hygienic phase). J Clin Periodontol. 1991 Apr;18(4):233-9.

20. Hou GL, Tsai CC. Clinical observations of the effects of nonsurgical periodontal therapy on human periodontal disease. II. Ultrasonic scaling and root planing for 6 months. Gaoxiong Yi XueKeXueZaZhi. 1989 Feb;5(2):72-86.

21. Haffajee $A D$, Cugini MA, Dibart $S$, Smith $C$, Kent RL Jr, Socransky SS. The effect of SRP on the clinical and microbiological parameters of periodontal diseases. J Clin Periodontol. 1997 May;24(5):324-34.

22. Ximénez-Fyvie LA, Haffajee AD, Som S, Thompson M, Torresyap G, Socransky SS. The effect of repeated professional supragingival plaque removal on the composition of the supraand subgingival microbiota. J Clin Periodontol. 2000 Sep;27(9):637-47.

23. Borrajo JL, Varela LG, Castro GL, Rodríguez-Nuñez I, Torreira MG. Diode laser $(980 \mathrm{~nm})$ as adjunct to scaling and root planing. Photomed Laser Surg. 2004 Dec;22(6):509-12.

24. LeBeau J. Laser technology: its role in treating and managing periodontal disease. Compend Contin Educ Dent. 2012 May;33(5):370-1.

25. Bach G, Neckel C, Mall C, Krekeler G. Conventional versus laser-assisted therapy of periimplantitis: a five-year comparative study. Implant Dent. 2000;9(3):247-51.

26. Gregg RH 2nd, McCarthy DK. Eight-year retrospective review of laser periodontal therapy in private practice. Dent Today. 2003 Feb;22(2):74-9.

27. Moritz A, Gutknecht N, Doertbudak O, Goharkhay K, Schoop U, Schauer P, Sperr W. Bacterial reduction in periodontal pockets through irradiation with a diode laser: a pilot study. J Clin Laser Med Surg. 1997 Feb;15(1):33-7.

28. Moritz A, Schoop U, Goharkhay K, Schauer P, Doertbudak
O, Wernisch J, Sperr W. Treatment of periodontal pockets with a diode laser. Lasers Surg Med. 1998;22(5):302-11.

29. Saglam M, Kantarci A, Dundar N, Hakki SS. Clinical and biochemical effects of diode laser as an adjunct to nonsurgical treatment of chronic periodontitis: a randomized, controlled clinical trial. Lasers Med Sci. 2014 Jan;29(1):37-46.

30. Romanos GE, Henze M, Banihashemi S, Parsanejad HR, Winckler J, Nentwig GH. Removal of epithelium in periodontal pockets following diode $(980 \mathrm{~nm})$ laser application in the animal model: an in vitro study. Photomed Laser Surg. 2004 Jun;22(3):177-83.

31. Kamma JJ, Vasdekis VG, Romanos GE. The effect of diode laser $(980 \mathrm{~nm})$ treatment on aggressive periodontitis: evaluation of microbial and clinical parameters. Photomed Laser Surg. 2009 Feb;27(1):11-9.

32. Gojkov-Vukelic M, Hadzic S, Dedic A, Konjhodzic R, Beslagic E. Application of a diode laser in the reduction of targeted periodontal pathogens. Acta Inform Med. 2013 Dec;21(4):237-40.

33. Kreisler M, Al Haj H, d'Hoedt B. Clinical efficacy of semiconductor laser application as an adjunct to conventional scaling and root planing. Lasers Surg Med. 2005 Dec;37(5):3505 .

34. Angelov N, Pesevska S, Nakova M, Gjorgoski I, Ivanovski $\mathrm{K}$, Angelova D, Hoffmann O, Andreana S. Periodontal treatment with a low-level diode laser: clinical findings. Gen Dent. 2009 Sep-Oct;57(5):510-3.

35. Caruso U, Nastri L, Piccolomini R, d'Ercole S, Mazza C, Guida $L$. Use of diode laser $980 \mathrm{~nm}$ as adjunctive therapy in the treatment of chronic periodontitis. A randomized controlled clinical trial. New Microbiol. 2008 Oct;31(4):513-8.

36. Giannelli M, Formigli L, Lorenzini L, Bani D. Combined photoablative and photodynamic diode laser therapy as an adjunct to non-surgical periodontal treatment. A randomized splitmouth clinical trial. J Clin Periodontol. 2012 Oct;39(10):96270.

37. Pejcic A, Kojovic D, Kesic L, Obradovic R. The effects of low level laser irradiation on gingival inflammation. Photomed Laser Surg. 2010 Feb;28(1):69-74.

38. De Micheli G, de Andrade AK, Alves VT, Seto M, Pannuti $\mathrm{CM}$, Cai S. Efficacy of high intensity diode laser as an adjunct to non-surgical periodontal treatment: a randomized controlled trial. Lasers Med Sci. 2011 Jan;26(1):43-8.

39. Dukić W, Bago I, Aurer A, Roguljić M. Clinical Effectiveness of Diode Laser Therapy as an Adjunct to Non-Surgical Periodontal Treatment: A Randomized Clinical Study. J Periodontol. 2012 Oct 17.

40. Ejiri K, Aoki A, Yamaguchi Y, Ohshima M, Izumi Y. High frequency low-level diode laser irradiation promotes proliferation and migration of primary cultured human gingival epithelial cells. Lasers Med Sci. 2014 Jul;29(4):1339-47.

41. Passanezi E, Diamante CA, de Rezende ML, Greghi SL. Lasers in periodontal therapy. Periodontol. 2000. 2015 Feb;67(1):268-91.

42. Fujimura T, Mitani A, Fukuda M, Mogi M, Osawa K, Takahashi S, Aino M, Iwamura Y, Miyajima S, Yamamoto H, Noguchi T. Irradiation with a low-level diode laser induces the developmental endothelial locus-1 gene and reduces proinflammatorycitokines in epithelial cells. Lasers Med Sci. 2014 May;29(3):987-94.

43. Benedicenti S, Pepe IM, Angiero F, Benedicenti A. Intracellular ATP level increases in lymphocytes irradiated with infrared laser light of wavelength $904 \mathrm{~nm}$. Photomed Laser Surg. 2008 Oct;26(5):451-3.

44. Soares DM, Ginani F, Henriques AG, Barboza CA. Effects of laser therapy on the proliferation of human periodontal ligament stem cells. Lasers Med Sci. 2013 Sep 7.

45. Conlan MJ, Rapley JW, Cobb CM. Biostimulation of wound 
healing by low-energy laser irradiation. A review. J Clin Periodontol. 1996 May;23(5):492-6.

46. Choi EJ, Yim JY, Koo KT, Seol YJ, Lee YM, Ku Y, Rhyu IC, Chung CP, Kim TI. Biological effects of a semiconductor diode laser on human periodontal ligament fibroblasts. J Periodontal
Implant Sci. 2010 Jun;40(3):105-10.

47. Castro GL, Gallas M, Núñez IR, Borrajo JL, Varela LG. Histological evaluation of the use of diode laser as an adjunct to traditional periodontal treatment. Photomed Laser Surg. 2006 Feb;24(1):64-8. 